\title{
Direct Observation of Zirconium Alloy Oxidation at the Nanoscale
}

\author{
Elizabeth Kautz ${ }^{1}$, Sten Lambeets ${ }^{2}$, Bharat Gwalani $^{3}$, Libor Kovarik $^{2}$, Daniel Perea $^{2}$, Arun Devaraj $^{3 *}$ \\ ${ }^{1}$ National Security Directorate, Pacific Northwest National Laboratory, Richland, WA \\ ${ }^{2}$ Earth \& Biological Sciences, Pacific Northwest National Laboratory, Richland, WA \\ ${ }^{3}$ Physical and Computational Sciences Directorate, Pacific Northwest National Laboratory, Richland, \\ WA \\ *Corresponding author: arun.devaraj@pnnl.gov
}

Zirconium ( $\mathrm{Zr}$ )-based alloys are commonly used in the nuclear industry for a variety of applications, such as nuclear reactor fuel cladding in pressurized water reactors, and as a hydrogen isotope absorbing material in tritium producing burnable absorber rods (TPBARs). $\mathrm{Zr}$ alloys are widely used in such applications due to their favorable mechanical behavior (e.g. yield strength, fracture toughness, creep, etc.), corrosion resistance, and low thermal neutron cross-section [1]. Despite these many desirable properties, corrosion of $\mathrm{Zr}$ alloys can limit component lifetime. A better understanding of oxide formation mechanisms and kinetics could thus enable improved alloy design and predictive capabilities related to fuel assembly degradation, such in a reactor operating environment, in spent fuel storage pools, or during an accident scenario (e.g. Fukushima-Dai Ichi, Three Mile Island, and Chernobyl).

Traditionally, oxidation kinetics of $\mathrm{Zr}$ alloys are studied in both pre- and post-transition regimes by performing long-term corrosion experiments (tens to hundreds of days) in which coupons are exposed to a corrosive environment, periodically removed, and weighed to measure coupon weight gain due to oxide formation as a function of exposure time [2]. While significant insight into $\mathrm{Zr}$ alloy oxidation can be obtained through such ex situ studies, there are inherent issues to these characterization efforts, particularly related to sample preparation and time scales for analysis.

Through use of a novel environmental reactor chamber connected to a local electrode atom probe (LEAP) via an environmental transfer hub (ETH), we are able to expose nanoscale volumes of Zircaloy4 to an oxygen gas atmosphere at elevated temperature, then analyze the oxide and oxide/metal (O/M) interface formed during very early stage of oxidation via APT [3]. This new approach, shown schematically in Figure 1(a), allows us to gain unique atomic-scale insight into: (1) initial, protective oxide stoichiometry formed, (2) O/M interfacial morphology, (3) alloy element concentration and partitioning adjacent to the $\mathrm{O} / \mathrm{M}$ interface.

Results from the present study are summarized in Figure 1(b). We find that the initial protective oxide layer formed during Zirc4 oxidation approaches a $\mathrm{Zr}: \mathrm{O}$ ratio of 2:1. This is distinctly different than the oxide layer formed in atmosphere during APT needle transfer ( $\mathrm{Zr}: \mathrm{O}$ ratio of 3:1). Additionally, we observe solute element partitioning ( $\mathrm{Sn}, \mathrm{Fe}$ ) during high temperature oxidation. Partitioning of such alloying elements could impact corrosion resistance and hydride formation in the Zircaloy-4 system. The APT observations are also correlated to complementary analysis of needle specimens in an aberration corrected transmission electron microscope to reveal the morphological and structural changes of oxide layer. This multimodal analysis of the early stages of oxidation by the two complimentary methods enabled a comprehensive atomic scale understanding of oxidation mechanism of Zircaloy-4 [4]. 


\section{References:}

[1] DO Northwood, Materials \& Design 6 (1985), p. 58.

[2] Y Dong, AT Motta and EA Marquis, Microscopy and Microanalysis 22 (2016), p. 1496.

[3] DE Perea et al., Advanced Structural and Chemical Imaging 3 (2017), p. 12.

[4] Acknowledgement: The work was performed at Pacific Northwest National Laboratory (PNNL), which is operated by Battelle for the United States Department of Energy (DOE). This research is funded by the Laboratory Directed Research and Development (LDRD) program at PNNL. A portion of this work was performed using EMSL, a national scientific user facility sponsored by DOE's Office of Biological and Environmental Research located at PNNL.

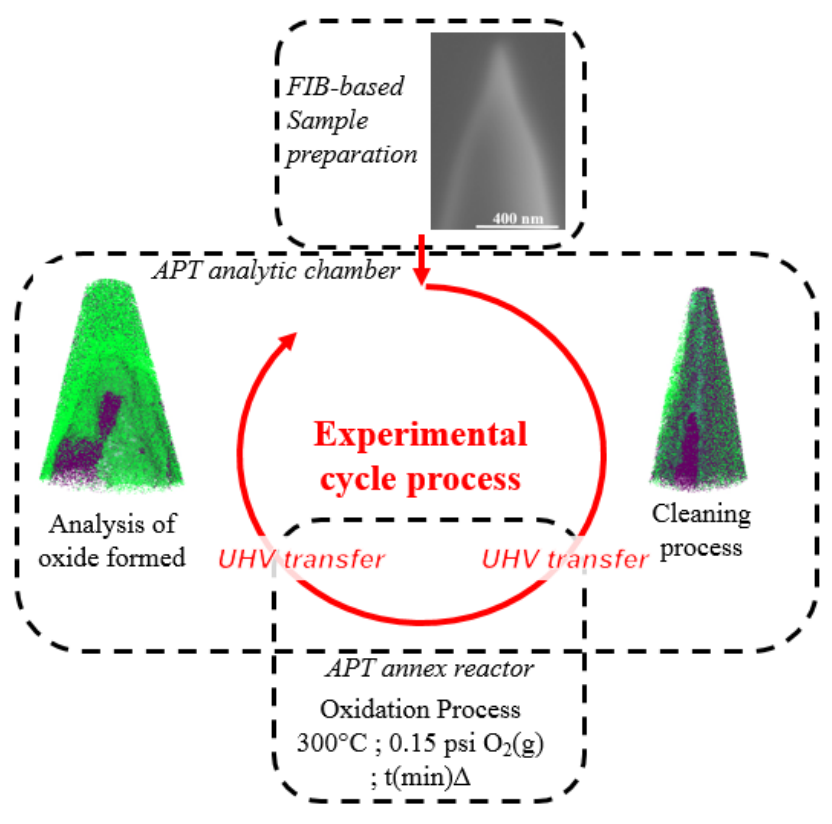

(a)

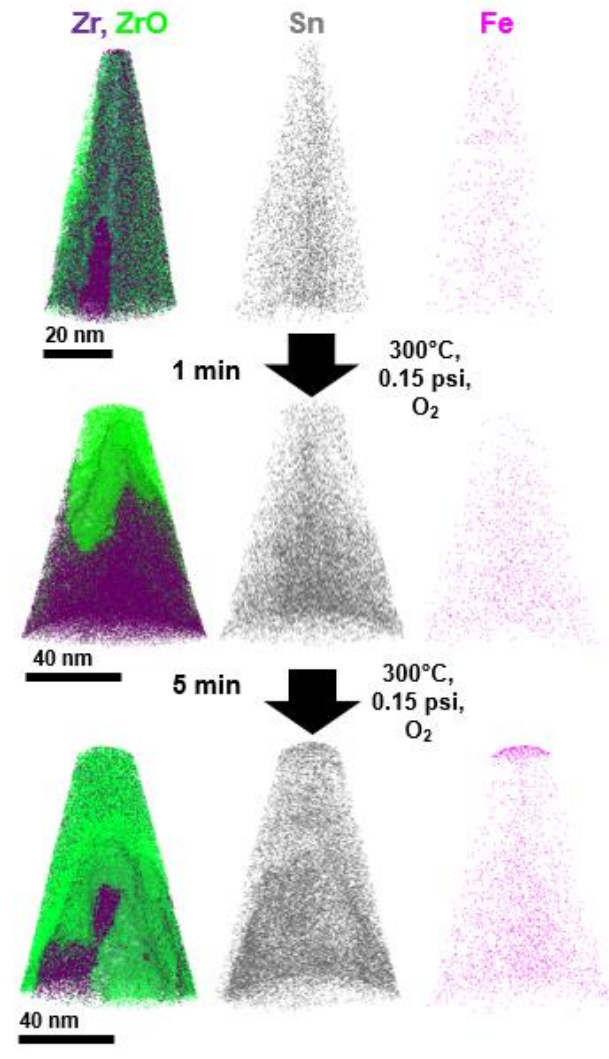

(b)

Figure 1. (a) Schematic of in situ oxidation and analysis via APT and an annex reactor system. (b) Summary of results from oxidation of Zirc4 via the method shown in (a). Element distribution maps for $\mathrm{Zr}, \mathrm{ZrO}, \mathrm{Sn}$, and $\mathrm{Fe}$ are shown for before oxidation, and after 1 and 5 minutes exposures to $300^{\circ} \mathrm{C}$, $0.15 \mathrm{psi}, \mathrm{O}_{2}$ gas. Element distribution maps show oxide film formation on the needle specimen, and $\mathrm{Sn}$ and $\mathrm{Fe}$ partitioning as oxidation time increases. 